\title{
Precisiones al correr el velo de una persona moral $^{1}$
}

\section{Accuracies of Disregard of the Legal Entity}

\section{Camilo Enrique Cubillos Garzón²}

\section{RESUMEN}

Si bien es cierto, todo asunto jurídico trae consigo consecuencias en el ordenamiento legal, también podemos advertir que dichas cuestiones se ven reflejadas en escenarios diferentes como el campo económico y social, debido a que el impacto que generan aquellas cuestiones son de tal trascendencia que es menester dedicarle unas líneas.

De acuerdo con esto, el tema a tratar es la regulación de la teoría del levantamiento del velo corporativo en las personas jurídicas en el Ordenamiento colombiano, así como las consecuencias que ésta genera, sirviéndose como herramienta de protección a terceros por razón del abuso de la figura societaria encaminada a defraudar los intereses de aquellos.

Palabras claves: Teoría del levantamiento del velo corporativo, personas jurídicas, protección a terceros, abuso de la figura societaria, administradores.

1 Fecha de recepción: 16 de septiembre de 2016. Fecha de aceptación: 14 de diciembre de 2016. Para citar el artículo: Cubillos, C. "Precisiones al correr el velo de una persona moral", Revist@ E-Mercatoria, vol. 15, N², julio-diciembre, 2016. DOI: https://doi.org/10.18601/16923960.v15n2.01

2 Profesor investigador de la Universidad Externado de Colombia. Abogado y Especialista en Derecho de los Negocios de la misma Universidad, Master en Derecho de la Empresa MADE (Universitat Pompeu Fabra, Barcelona), Doctorado en Derecho con especialidad en Derecho Patrimonial (Universitat Pompeu Fabra, Barcelona).Camilo.cubillos@uexternado. edu.co. Con la colaboración del monitor del Departamento de Derecho Comercial de la Facultad de Derecho de la Universidad Externado de Colombia: Juan José Sotelo Enríquez. 


\section{ABSTRACT}

While any legal matter has consequences in the legal system, we can also note that these issues are reflected in different scenarios to the already mentioned, like in an economic and social, because the impact generated by these are such importance that it is necessary to dedicate a few lines to this matters.

Accordingly, the issue to be addressed is the regulation of the theory of disregard of the legal entity in the Colombian legal system, as well as the consequences that generates, used as a tool of protection to creditors by reason of abuse to the form of the company focused to defraud the interests of those.

Key Word: theory of disregard of the legal entity, corporations, protection to creditors, abuse to the form of company, administrators.

\section{INTRODUCCIÓN}

Los asuntos jurídicos de actualidad no dejan de ser cuestiones discrepantes en la medida en que pueden implicar una serie de inconvenientes por cuanto generan ciertos desacuerdos jurídicos y también económicos.

Es precisamente aquel punto el que deseo exponer en estas líneas, trayendo a colación un comentario sobre un artículo titulado "El Alcohólico y su Botella" del jurista español Francisco Sosa Wagner (http://garciamado. blogspot.com/2010/05/el-alcoholico-y-su-botella-por.html 20/08/14), quien sostuvo que era necesario ajustar el sistema económico en la medida en que no siempre su crecimiento terminaba siendo igual al bienestar social y además cuando el desarrollo se hacía indefinido, en ocasiones terminaba debilitando la referida prosperidad.

Aquel modelo de valoración mercantil es aplicable cuando se comprende que todo beneficio económico implica un bienestar y además, porque a nivel global, se ha expuesto la necesidad de apreciar los métodos de todo comportamiento, considerando que el crecimiento permanente del sistema económico, carece de sentido cuando la mesura o la sensatez no son parte integrante de su propio desarrollo.

Este fue uno de los raciocinios por los que se citó aquella máxima popular que indicaba que una parte de nuestro sistema negociable, incluyendo el jurídico, obedecía también a un crecimiento económico de tal envergadura que sería similar al que llegaba a acontecer en el caso en el que están "los alcobólicos de la botella o los drogadictos de la aguja" (sic), citado en el artículo en mención.

Así las cosas, iniciaré el desarrollo de este apartado considerando aquella concepción que especifica cuál es el fin último de la personalidad jurídica, partiendo desde una aproximación para luego concebir en qué medida son apreciables los objetivos que desarrollan los órganos que integran el ente jurídico así como los sujetos que hacen parte él, en este estado, cabe hacer 
la salvedad del rechazo por aquella concepción que considera aquel vínculo, como el resultado de un contrato pero dejando para otra oportunidad, aquella disertación jurídica.

Con aquel otro planteamiento, se pretende plasmar una posición categórica en procurar determinar que cuando se abuse de una persona moral o jurídica, de manera independiente a la estructura empresarial, legítima, es conveniente obtener el resarcimiento ajustado del daño causado a un tercero o al mismo ente jurídico.

Pese al deseo compensatorio, cabe señalar el interés manifiesto por hacer valer la justicia material sobre la inseguridad que acarrea la sumisión a la formalidad, la cual pese a tener el asidero jurídico, no sirve de puente auxiliador para con las actuaciones fraudulentas o simuladas, dando origen de esta manera a la corriente doctrinal de la Ruptura del Hermetismo de la Personalidad Jurídica.

\section{GENERALIDADES DE LA PERSONIFICACIÓN JURÍDICA}

No es suficiente la interpretación que se da a la figura de la personalidad jurídica, por tanto, es acertado aquel razonamiento en la medida en que se desnaturaliza el fin último de los propósitos con los que se le dio vida jurídica a la persona moral. Ahora bien, en razón del enfoque que se pretende dar en estas líneas es necesario adentrarnos al interior de la personalidad jurídica, pero desde una perspectiva próxima a los mismos instrumentos que hacen parte de la administración empresarial.

\section{A. En Relación con la Gestión de la Persona Moral}

Desde los orígenes de Derecho Romano y cuando las actividades de los sujetos eran operadas alrededor de la concepción de la gestio, esta figura se concibió como la administración de los negocios del pupilo (dominus negotii) por parte del tutor (gestor) ${ }^{3}$ sin recibir encargo alguno de su titular; asemejándose así el modelo del cuasicontrato al del contrato de mandato en la medida que al no existir acuerdo de voluntades, se mantenían unas consecuencias similares como la responsabilidad existente del gestor (negotiorum getio) ${ }^{4}$.

El hecho de actuar en nombre de otro se halla reflejado en la figura jurídica del mandatum ${ }^{5}$, por tanto, al tratarse del negocio consensual de la societas ${ }^{6} \mathrm{y}$ del

3 PETIT, Eugene. Tratado Elemental de Derecho Romano. Novena edición. Editorial Cholos. Buenos Aires. 1924. p. 137.

4 IGLESIAS, Juan. Derecho Romano. Instituciones de Derecho Privado. Sexta Edición. Ed. Ariel. Barcelona. 1972. p. 461.

5 GUZMÁN BRITO, Alejandro. Derecho Privado Romano. Vol. 2. Ed. Jurídica de Chile. Santiago de Chile. 1996. Pág. 189.

6 En consideración con la societate, frente a una empresa individual y colectiva, bien puede 
hecho de que el ente no era considerado una persona jurídica al no tener voluntad propia y no poder ser representado, era un deber que fuese gestionado por cada socio en particular?.

Así las cosas, se determinó que no solo quienes operaban en una representación eran garantes por cuanto también cabría la culpabilidad de quienes se encontraban como representados; sobre aquella forma de interpretación, puede consultarse la obra de autores como MAZEAUD y TUNC, para quienes ha existido la consideraron de comprender la responsabilidad entorno a la explicación de los hechos ajenos, haciendo de la misma forma responsables a quienes se encuentran representados ${ }^{8} \mathrm{y}$ no de manera directa a su representante ${ }^{9}$.

\section{B. El Hermetismo de la Personalidad}

Como consecuencia de la responsabilidad debe valorarse la gestio de un ente jurídico desde una órbita tan compleja como la existente en el propio hermetismo de la personalidad ${ }^{10}{ }_{i}$ convirtiéndose aquel enfoque en un problema a la hora de emplear a una persona moral para abusar frente a terceros e incluso ante el mismo ente jurídico.

Los inconvenientes que se advierten al entrever el hermetismo de aquel ente jurídico parten desde la maniobra de resguardarse en factores formales, como la reserva con la que fue considerada la constitución de la sociedad en cuanto al manejo patrimonial de los aportes a la compañía y el capital personal de cada socio, hasta la responsabilidad en la administración del mismo ente cuando se derivó de un contrato; creándose de esta forma un vacío entre de la justicia material frente a la seguridad jurídica de la aplicación formal.

consultarse la obra de CERAMI Pietro, DI PORTO, Andrea y PETRUCCI, Aldo. Diritto Comerciales Romano. Profilio Storico. Edición 2a. ed. G. Giappichelli Editore. Torino. 2004. pp. 61-63.

7 No obstante lo esbozado en esta oportunidad y con un ánimo aclaratorio, es prudente advertir que pese a actuar en nombre propio cada socio, en ellos existe el deber de comunicación con los demás integrantes de la colectividad, lo que en mi parecer representaría

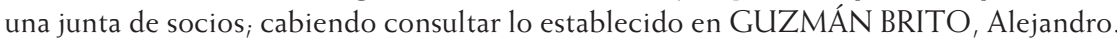
Ob. Cit. pp. 183 y ss.

8 MAZEAUD, Henri y León y TUNC, Andre. Tratado Teórico y Práctico de la Responsabilidad Civil Delictual y Contractual. Tomo I. Volumen II. Ediciones Jurídicas Europa - América. Buenos Aires. 1962. pp. 704 y ss.

9 NEPPI, Vittorio. Causalidad Jurídica y Representación. Ediciones Jurídicas Europa - América. Buenos Aires. 1962. pp. 87 y ss.

10 Una aproximación al hermetismo de la personalidad se halla en la descripción que del mismo se hace para significar el resultado antagónico entre los intereses de la persona moral y los de sus miembros, lo que significaría el interés particular de los miembros y del ente personificado. BOLDÓ RODA, Carmen. Levantamiento del Velo y Persona Jurídica en el Derecho Privado Español. Edición 3ª. Ed. Aranzadi. Navarra. 2000. pp. 40 y ss. 
Sobre el sentido inadecuado de percibir el hermetismo de la persona moral es de recordar como, en otros artículos, se esbozó la concepción de profesionalizar la figura del administrador de una persona jurídica" ${ }^{11}$, así como la interpretación incorrecta de la Teoría del Levantamiento del Velo Corporativo, entre otras expresiones.

Ahora bien, sobre la errada significación en el sistema jurídico colombiano se estableció que la teoría del levantamiento no solo existía para romper el hermetismo de la personalidad ${ }^{12}$ en razón del comportamiento abusivo de los socios $^{13}$ sino que se concebía también levantar el velo cuando se pretendiera hallar la responsabilidad de los administradores ${ }^{14}$.

En este estado del escrito, es oportuno recordar el desarrollo histórico de la teoría del disregard of the legal entity ${ }^{15} \mathrm{y}$ el comprender que este postulado se halla en nuestro Ordenamiento mercantil desde hace más de una década (Ley 222 de 1995 -L.222/95 $)^{16}$, cuando se partía de la base de la responsabilidad de la controlante en razón de la dependencia (Artículo -Art.- 148 -ParágrafoL.222/95) ${ }^{17}$ y de los bienes insuficientes para liquidar una sociedad (Art. 207 L.222/95).

11 La profesionalización de la actividad de los administradores es una tarea que se ha desarrollado y a su vez evolucionado a lo largo de nuestro estadio mercantil, sobre este asunto puede consultarse NARVÁEZ GARCÍA, José Ignacio. Teoría General de las Sociedades, 3a ed., Bogotá, Editorial Librería del Profesional.1980. Pág. 295. CUBILLOS GARZÓN, Camilo Enrique. ¿Profesionalización de un Encargo Societario? Universidad Externado de Colombia. Departamento de Derecho Comercial. Revist@ E-Mercatoria Volumen 9, Número 2. 2010. pp. 2-15.

12 Verbi gratia, cuando se trata de la sociedad por acciones simplificada (SAS), entre otros entes jurídicos.

13 Para un estudio más detallado sobre la Teoría del Disregard of the Legal Entity, resulta aconsejable mirar el planteamiento que se hace sobre las tres grandes categorías que pueden significar un abuso de la personalidad jurídica. SERICK, Rudolf. Apariencia y Realidad en las Sociedades Mercantiles. El Abuso del Derecho por medio de las Personalidad Jurídica. Trad. PUIG BRUTAU, Prólogo POLO. Ed, Ariel. Barcelona. 1958. Citado por BOLDÓ RODA, Carmen. Ob. Cit. pp. 72-76.

14 CUBILlOS GARZÓN, Camilo Enrique. Comentarios en torno al Allanamiento de la Personalidad Jurídica en las Sociedades por Acciones Simplificadas. Universidad Externado de Colombia. Departamento de Derecho Comercial. Revist@ E-Mercatoria Volumen 8, Número 2. 2010. pp. 11-18.

15 En aras del entendimiento, es valioso apoyarse en la sucinta pero correcta explicación expuesta en la Sentencia 801-000055 de 16 de octubre de 2013 de la Superintendencia de Sociedades y que se halla presente en la pp. 22/42. IV. 1., A. La interposición societaria en el derecho comparado.

16 SOTOMENTE MUJICA, David y CUBILLOS GARZÓN, Camilo. Teoría del Levantamiento del Velo Corporativo (Tesis de Grado). Universidad Externado de Colombia. Bogotá. 1997. pp. 74-78.

17 NAMÉN VARGAS, William. Despersonificación y Responsabilidad Societaria. Congreso Internacional. La Despersonificación Societaria y el Régimen de la Responsabilidad. Pontificia Universidad Javeriana. Bogotá. 2004. pp. 236-245. 
En los parámetros de responsabilidad trazados por la citada Ley a través de la cual se modificó el libro II del Código de Comercio (C.Co.) y se expidió un régimen para los procesos concursales, se determinó (Art. 71. PAR. L.222/95) que cuando una empresa unipersonal hubiese sido empleada en fraude a la ley o en perjuicio de terceros, no simplemente respondería el titular de las cuotas de capital, entendiendo como tal la calidad de asociado, sino que además responderían los administradores que alcanzaren a abusar de ella ${ }^{18}$.

"(...) PAR. —Cuando se utilice la empresa unipersonal en fraude a la ley o en perjuicio de terceros, el titular de las cuotas de capital y los administradores que bubieren realizado, participado ofacilitado los actos defraudatorios, responderán solidariamente por las obligaciones nacidas de tales actos y por los perjuicios causados. (...)" Resaltado en cursiva por fuera de texto.

Sobre este aspecto en particular, cabe anotar que aquel planteamiento normativo desconoce que el bermetismo de la personalidad jurídica ${ }^{19}$ está haciendo mención es a la reserva que caracteriza a la persona moral o a la negativa en el sigilo del actuar fraudulento, bajo el manto de la Teoría Organicista empleado por los asociados para proteger el patrimonio personal a través de los aportes realizados ${ }^{20}$.

En definitiva, la desestimación de la personalidad moral ha sido entendida como una medida de fiscalización judicial que permite hacer extensible la responsabilidad únicamente a los socios de aquellos entes jurídicos por los mismos hechos del abuso o el fraude; de esta manera fue entendido por parte de la Superintendencia de Sociedades ${ }^{21}$

18 Concretamente y sobre este particular puede consultarse aquella visión crítica expuesta en CUBILLOS GARZÓN, Camilo Enrique. Comentarios en torno al Allanamiento de la Personalidad Jurídica en las Sociedades por Acciones Simplificadas. Ob. Cit. pp. 11-18.

19 El hermetismo de la personalidad es aquella cualidad impenetrable o la singularidad existente en la apreciación de la persona jurídica, ya que aquel ente que ha nacido a la vida jurídica resultará ser, completa y universalmente, independiente de cada uno de los integrantes que la componen sin incorporar y fusionar al patrimonio de la persona moral, al patrimonium personae de cada uno de los socios o partícipes de la persona jurídica.

20 DE ANGEL YAGÜEZ, Ricardo. La Doctrina del "Levantamiento del Velo" de la Persona Jurídica en la Jurisprudencia. $4^{a}$ Ed. Ed. Civitas. Madrid. 1997. pp. 305 y ss.

21 Sentencia 801-000015 de 15 de marzo de 2013 de la Superintendencia de sociedades. "(...) Una solución más idónea para contrarrestar el abuso de la sociedad de capital consiste en introducir medidas de fiscalización judicial que permitan controvertir ex post las actuaciones indebidas de los empresarios. Esta alternativa tiene la ventaja de imponerle altos costos solamente a los sujetos que, con su conducta, desborden la finalidad para la cual fue diseñada la aludida figura societaria. Así, por ejemplo, mediante la denominada desestimación de la personalidad jurídica, las autoridades judiciales pueden hacerle extensiva, a los accionistas de una compañía, la responsabilidad por las obligaciones sociales insolutas, en hipótesis de fraude o abuso.(...)" Resaltado en cursiva-subrayado por fuera de texto. 
así como por la misma Corte Constitucional ${ }^{22}$ y el Consejo de Estado $^{23}$ de Colombia.

\section{LA JUSTICIA MATERIAL SOBRE LA SEGURIDAD JURÍDICA}

\section{A. Rasgos Societarios Característicos del Conflicto en la Justicia}

Por otra parte, aquella personificación clásica de las sociedades dotada de perfección consiguió desbordar la verja insuperable de lo jurídico al separar el umbral de lo reglamentario frente a la practicidad oscilante de los mercados. Sin embargo, no se puede permitir que el pragmatismo prevalezca sobre la justicia material, por el contrario, lo deseado resulta ser advertir que para el logro de aquel tipo de justicia, es deber hallar la vía legal de la observancia de la sistematización normativa ${ }^{24}$.

22 Pronunciamiento que fue vuelto a citar por parte de la misma entidad a través de la Sentencia 801-000023 de 24 de mayo de 2013 de la Superintendencia de sociedades; ambos basados en el Auto 801-017366 de 10 de diciembre de 2012 de la de la Superintendencia de sociedades, según Sentencia 800-000055 de 16 de octubre de 2013 de la de la Superintendencia de sociedades.

Sentencia C-865 de 2004 de la Corte Constitucional.

Cuando se vulnera el principio de buena fe contractual y se utiliza a la sociedad de riesgo limitado no con el propósito de lograr un fin constitucional válido, sino con la intensión de defraudar los intereses de terceros, el ordenamiento jurídico puede llegar a hacer responsables a los asociados, con fundamento en una causa legal distinta de las relaciones que surgen del contrato social. Es entonces en la actuación maliciosa, desleal o deshonesta de los accionistas generadora de un daño para con los terceros, en donde se encuentra la fuente para desconocer la limitación de la responsabilidad y exigir de los socios la reparación del daño acontecido. Por lo tanto, la finalidad del levantamiento del velo corporativo es desconocer la limitación de la responsabilidad de los asociados al monto de sus aportaciones, en circunstancias excepcionales ligadas a la utilización defraudatoria del beneficio de la separación.

23 Sentencia del 18 de septiembre de 2014 del Consejo de Estado, Sección Primera, C.P Marco Antonio Velilla Moreno.

La teoría del levantamiento del velo corporativo es conocida como una herramienta legal que permite dejar al descubierto la situación de protección de los socios ante una vulneración al principio de buena fe contractual generadora de un daño para con los terceros. La figura del velo corporativo, hace relación única y exclusivamente a la responsabilidad que les incumbe a los asociados de una persona jurídica, en donde es deber de ellos actuar con lealtad, honestidad, trasparencia en sus relaciones con los terceros que contratan con la sociedad y por ende solo ellos responden hasta el monto de sus aportes. Ahora bien, cuando los asociados de manera fraudulenta pretenden perjudicar a los terceros en general, es posible perseguir los bienes individuales de los asociados.

24 Sobre aquel particular viene a mi memoria un caso relevante por la significación que representó al tratarse del contexto de las inhabilidades de congresista y la decisión de decretar la perdida de investidura de un Senador por la violación de las restricciones perpetradas a través de una persona jurídica. Al respecto ver Sentencia del 13 de noviembre de 1997 del Consejo de Estado. 
No obstante lo anterior, la técnica del levantamiento del velo corporativo es un realismo jurídico dirigido a hacer prevalecer la justica material frente a la seguridad jurídica de lo reglamentario; por tanto, en el evento en que amparado en un tipo societario perfecto como es una sociedad de capital con un patrimonio social insuficiente o casi inexistente, resulta ser el allanamiento una teoría que hace posible vislumbrar la posibilidad de hacer imperar aquella justicia material frente al deseo de los actos defraudatorios ilícitos de $\operatorname{los} \operatorname{socios}^{25} \mathrm{y}^{26}$.

En este mismo orden, aparte de la disquisición jurídica sobre la validez de ejercer la acción de levantar el velo corporativo para resarcir el daño ocasionado en contra de un asociado o frente a un innecesario ${ }^{27}$ administrador ${ }^{28}$;

25 EMBID IRUJO, José Miguel. Abuso de la Forma Social y Levantamiento del Velo de 1 personalidad Jurídica: Algunas Reflexiones desde el Derecho Español. En Abuso de la Personalidad Societaria. Revista de Derecho Privado y Comunitario 2008-3. Edición 1 ${ }^{\text {a }}$. Ed. Rubinzal-Culzoni Editores. Buenos Aires. 2009. pp. 57-58.

26 Otro asunto que cabe traer a colación, a pesar del distanciamiento del orden jurídico mercantil, es el hecho de comprender cómo a través de la expedición de una norma se desconocen los mecanismos de control constitucional propios de la misma, sustrayendo de ésta la legalidad propia de una disposición empleando hasta un Decreto Reglamentario y controvirtiendo la interpretación de la Ley.

Respecto al conflicto suscitado al modificar a través de un Decreto Reglamentario la sistematización planteada que en principio resulta ser interior del Código de Comercio y su razonable así como fundada acción de nulidad que cabría poner en conocimiento del Consejo de Estado por tratarse al mismo tiempo de una elusión de constitucionalidad, es oportuno indicar que se están usurpando las reservas legales, así como suprimiendo el debate democrático y por lo tanto se está evitando un control de constitucionalidad. Sobre aquel particular, puede consultarse la obra de QUINCHE RAMÍREZ, Manuel Fernando. La elusión constitucional. Una política de evasión del control constitucional en Colombia. $2^{\mathrm{a}}$ ed. Ed. Universidad del Rosario. Bogotá. 2009. CUBILLOS GARZÓN, Camilo Enrique. La Teoría del Levantamiento del Velo Corporativo en los Grupos Societarios. $1^{\text {a }}$ Ed. Ed. Universidad Externado de Colombia. Bogotá. 2016. pp. 70 y 71.

27 Se recurre a aquel calificativo insustancial y que se expresa frente al gestor, en razón a que se trata de un asunto en el cual ya existían mecanismos armónicos para lograr aquel reparo tratándose de un abuso de la personalidad por parte de un administrador; concretamente me refiero a la funcionalidad y aplicabilidad que generaría las ya existentes Acciones Sociales e Individuales de Responsabilidad contra los Administradores. Al respecto PINO SOLANO, María Mónica ${ }_{i}$ HENAO BELTRÁN, Lina Fernanda ${ }_{i}$ ARIAS BARRERA, Ligia Catherine y CUBILLOS GARZÓN, Camilo. Directrices del Régimen de Responsabilidad de los Administradores de Sociedades. Universidad Externado de Colombia. Departamento de Derecho Comercial. Revist@ E-Mercatoria Volumen 8, Número 1. Bogotá. 2009.pp. 21-30

28 En el sentido de no recurrir a la figura del Disregard of the Legal Entity para alcanzar la solidaridad de los administradores, se puede apreciar los señalado por RODRÍGUEZ MANCINI, Jorge. La Doctrina de la Penetración de la Personalidad Jurídica. Responsabilidad de los Administradores y de los Grupos Económicos en la Jurisprudencia de la Cámara Nacional de Apelaciones del Trabajo. En Abuso de la Personalidad Societaria. Revista de Derecho Privado y Comunitario 2008-3. Edición 1ª. Ed. Rubinzal-Culzoni Editores. Buenos Aires. 2009. pp. 525 y ss. 
es preocupante también el asunto de emplear medios inconstitucionales para modificar las normas propias del Ordenamiento Mercantil a través de Decretos Reglamentarios, no dejando de ser alarmante la desnaturalización de figuras mercantiles como la de los Grupos Societarios o Empresariales (Grupos).

Concretamente, el Decreto Reglamentario 1749 del 26 de mayo de 2011 (Dec.1749/11) con el que se reglamentó la Ley 1116 de 2006 (L.1116/06), introdujo una serie de vacíos jurídicos inconstitucionales por cuanto por una parte no definió los campos de acción y por otra no entró a precisar el tema jurídico-económico de los grupos ${ }^{29}$; dejando de esta manera la puerta abierta para entender que estamos en presencia de aquellos fenómenos económicos, cuando existe solamente uno de los requisitos de existencia ${ }^{30}$ como resulta ser el "control"31.

29 En otra oportunidad se retornará la disquisición jurídica sobre la deteriorada y primitiva interpretación hecha del Grupo Empresarial, desconociendo en el Art. 2 \# 1 del Dec.1749/11 (Ver Pie de Página No. 30) uno de los elementos básicos o esenciales para la existencia de un Grupo de Sociedades cual es la Unidad de Propósito y Dirección, limitándose a considerar la existencia del mismo simplemente cuando nos hallamos frente a una situación

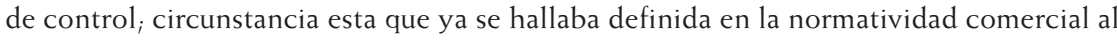
tratar el asunto de las presunciones de subordinación consagradas en el artículo 261 del C.Co.

30 Sobre el significado y la necesaria participación del control así como de la dirección unitaria en la conformación de un grupo, se puede apreciar la importancia dada a los mismos como elementos propios de un grupo en parte de la doctrina como resultan ser los trabajos de: EMBID IRUJO, José Miguel. Introducción al Derecho de los Grupos de Sociedades. Ed. Comares. Granada 2003. pp. 8-14.

GIRGADO PERANDONES, Pablo. La Empresa de Grupo y el Derecho de Sociedades. Ed. Comares. Granada. 2001. pp. 223 y ss

Sin embargo, con una consideración próxima más no sinónima por cuanto se le da mayor prevalencia a la unidad de propósito y dirección que al elemento del control se encuentra: MANÓVIL, Rafael Mariano. Evolución del Derecho de los Grupos de Sociedades. $1^{a}$ ed. Ed. Biblioteca Academia Nacional de Derecho y Ciencias Sociales de Buenos Aires. Serie IV. Instituto de Derecho Empresarial. Buenos Aires: La Ley, 2005. XIV, p. 7.

31 Articulo 2. Numeral 1. Dec.1749/11. Definiciones.

"(...) 1. Grupo de Empresas: Es el conjunto integrado de personas naturales, personas jurídicas, patrimonios autónomos, o entes de cualquiera otra naturaleza que intervienen en actividades de carácter económico, vinculados o relacionados entre sí por su carácter de matrices, controlantes o subordinadas, o porque la mayor parte de sus capitales pertenece (Artículo 261.- Modificado. L. 222/95, art. 27. del >C.Co. Presunciones de subordinación) o está bajo la administración de las mismas personas jurídicas o naturales (Artículo 261 Numeral 1 del C.Co.), ya sea porque obran directamente o por conducto de otras personas, o de patrimonios autónomos (Artículo 261 Numeral 2 del C.Co.). Así mismo, se entiende que forman parte de un Grupo de Empresas aquellos vinculados entre sí porque son garantes unos de otros y las empresas que se encuentren en los supuestos establecidos en el artículo 32 de la Ley 1116 de 2006. (Artículo 261 Numeral 3 del C.Co.) $(\ldots)^{\prime \prime}$ Resaltado en negrilla, cursiva, subrayado y entre paréntesis por fuera de texto. Sobre el particular, no quisiera concluir este apartado sin antes por lo menos lo menos mencionar la existencia de un conflicto jurídico sobre la figura de los patrimonios autó- 


\section{B. Complejidades Jurídicas Frente a la Reglamentación Societaria.}

Una vez expuesto lo que en mi parecer resulta ser un claro ejemplo de inconstitucionalidad así como el hecho de no interpretar en debida forma una visión económica-societaria como es la de un grupo, es el momento acertado para establecer cómo el Decreto Reglamentario en discusión perturba el orden jurídico mercantil.

Al iniciar este escrito, se trazó unas delgadas pero a su vez demarcadas líneas sobre las que debía entenderse el significado de la teoría del levantamiento del velo de la personalidad jurídica y en razón de ello se definió la citada teoría como aquellas condiciones en virtud de las cuales era concebida como una escisión patrimonial ${ }^{32}$.

No obstante, la teoría del allanamiento permitió levantar aquella reserva societaria en el evento en el que se empleara dicha personalidad jurídica en aras de defraudar o en perjuicio de terceros, tal y como en nuestra legislación fue advertido por la misma Corte Constitucional, el Consejo de Estado o la Superintendencia de Sociedades ${ }^{33}$.

Entretanto y bajo estas condiciones, es posible desenmascarar aquella personalidad, con el único fin de hacer responsables a quienes se valieron de toda una institución societaria; sin embargo, a pesar de la aludida concepción de hacer responsables a los asociados y a los "innecesarios" administradores, es deber observar en que medida existiría dicha responsabilidad.

Sobre el Art. 25 del ya referido Dec.1749/11, cabe señalar el planteamiento existente pero a su vez impertinente a la hora de entrever la consolidación patrimonial, todo ello por cuanto se trata de una modalidad de levantamiento del velo en la medida en que hace responsables a los socios de una persona moral, con la ya aludida reserva del administrador ${ }^{34}$.

nomos o la operatividad del elemento de la subordinación en aquellas figuras fiduciarias o en las mismas personas naturales.

32 Entendiendo aquel tipo de escisión como la separación entre el patrimonio de los asociados con el de la persona jurídica, haciéndose de esta forma responsables aquellos sujetos hasta por el monto de lo aportado, salvo que los mismos hubiesen abusado de la personalidad jurídica.

33 Pronunciamiento que fue vuelto a citar por parte de la misma entidad a través de la Sentencia 801-000023 de 24 de mayo de 2013 de la Superintendencia de sociedades; ambos basados en el Auto No. 801-017366 de 10 de diciembre de 2012 de la de la Superintendencia de sociedades, según Sentencia 800-000055 de 16 de octubre de 2013 de la de la Superintendencia de sociedades. Ver Pie de Página Nos. 20, 21 y 22.

34 "(...) Artículo 25. Consolidación patrimonial. Los procesos de insolvencia de los partícipes de un Grupo de Empresas deberán respetar la identidad jurídica propia de cada partícipe, salvo en el caso de una liquidación judicial en donde (...) el juez del concurso (...) ordene una consolidación patrimonial, siempre y cuando el solicitante acredite al menos una de las siguientes situaciones:

1. Que el activo y el pasivo del Grupo de Empresas en liquidación judicial, están de tal 
De igual forma, es de precisar que tratándose de procesos de insolvencia y bajo la precisión del referido Decreto Reglamentario (Art. 2 Numeral 1 del Dec. $\left.1749 / 11^{35}\right)$, un grupo no resulta ser otro asunto que una situación jurídicaeconómica de control.

Ordenándose de esta manera que cualquier participe -deudor- de un grupo, pueda disponer la realización de una consolidación patrimonial ${ }^{36}$ siendo y bajo mi consideración, una ruptura del hermetismo de la personalidad jurídica por considerar el patrimonio de cada uno de los integrantes del grupo un solo capital o una llana unión de sujetos vinculados entre sí por su carácter de controlantes y controladas ${ }^{37}$.

En este estado, es oportuno señalar que la teoría del levantamiento del velo, efectivamente, puede apreciarse cuando el numeral 2 del Art. 25 del Dec.1749/11 hace alusión, previa consideración de los comentarios fijados entorno al grupo, a la consolidación patrimonial cuando se demuestre la actividad fraudulenta ${ }^{38}$.

Sin resultar suficiente con la citada descripción, que a mi juicio era adecuada, el Art. 25 se adentra en una descripción sucinta de las operaciones"sin legitimidad comercial alguna" (Fraudulentas) y que se encuentran en los numerales $1,7,8$, o 9 del Art. 83 de la L. $1116 / 06^{39}$ o en las conductas que figuran

forma entremezclados que no podría deslindarse la titularidad de los bienes y de las obligaciones sin incurrir en un gasto o en una demora injustificados.

2. Que el insolvente partícipe del Grupo de Empresas practicó alguna actividad fraudulenta o ejecutó algún negocio sin legitimidad patrimonial alguna, que impidan el objeto del proceso y que la consolidación patrimonial sea esencial para enderezar dichas actividades o negocios. Para efectos de la aplicación de este numeral, las actividades fraudulentas o los actos o negocios sin legitimidad comercial alguna son los descritos en los numerales 1, 7, 8, o 9 del artículo 83 de la Ley 1116 de 2006, en el contexto de un Grupo de Empresas, o las conductas descritas en los numerales 1 a 9 señaladas en el artículo anterior. (...)" Resaltado en negrilla y cursiva por fuera de texto.

35 Ver Pie de Página No. 30.

36 Art. 2. Numeral 4. Dec.1749/11. Definiciones.

"(... 4. Consolidación patrimonial: Tratamiento excepcional en virtud del cual el pasivo y el activo de dos o más deudores vinculados entre sí o partícipes en un mismo Grupo de Empresas se entienden y tratan como parte de una única masa de la insolvencia. (...)" Resaltado en negrilla y en cursiva por fuera de texto.

37 Ver Pie de Página No. 30.

38 Ver Pie de Página No. 33.

39 Art. 83. L.1116/06. Inhabilidad para ejercer el comercio.

"(...) 1. Constituir o utilizar la empresa con el fin de defraudar a los acreedores.

(...)

7. La distracción, disminución, u ocultamiento total o parcial de bienes.

8. La realización de actos simulados, o cuando simule gastos, deudas o pérdidas.

9. Cuando sin justa causa y en detrimento de los acreedores, hubieren desistido, renunciado o transigido, una pretensión patrimonial cierta. (...)" Resaltado en cursiva por fuera de texto y que según el Art. 25. Numeral 2. (Dec.1749/11) haga alusión a los Grupos Empresariales. 
en los numerales 1 al 9 del Art. 24 del Dec.1749/11, previa consideración de mi posición frente a la administración ${ }^{40}$.

En definitiva, a lo largo de este escrito se han expuesto los asuntos de la administración societaria que han de ser valorados de una forma diferente, así como se ha indicado el por qué debe replantearse la manera de abordar la teoría del Disregard of the Legal Entity y la interpretación errada existente al entender los grupos como una simple situación de control, desconociendo aquella unidad en la coordinación de aquel, siempre será con el mismo propósito y en una misma dirección.

Sin embargo y a pesar de lo edificado hasta el momento, es necesario fijar nuestra atención en el acápite del Dec. 1749/11 del artículo 25 que estableció cómo en los procesos de insolvencia el juez del concurso de manera discrecional podrá ordenar la consolidación patrimonial, cuando se logre acreditar una situación fraudulenta (Numeral 2) o se consiga justificar que el patrimonio de los integrantes del grupo (situación de control) se encuentran "entremezclados"

40 Art. 24. Dec.1749/11. Responsabilidad Civil de los Socios en el Contexto de un Grupo de Empresas.

"(...) 1. Uso indebido o abuso por un participe del Grupo de Empresas del control que ejerce sobre otro participe del Grupo de Empresas, en provecho de la empresa controladora del Grupo de Empresas.

Conducta fraudulenta del socio o accionista controlante de un partícipe del Grupo de Empresas que consista en desviar, en provecho propio, partidas del activo de dicha empresa del Grupo de Empresas, aumentar su pasivo, o en administrarla con intención de defraudar a sus acreedores.

Explotación a un partícipe del Grupo de Empresas como fiduciario, agente o socio de la sociedad matriz o controladora del Grupo de Empresas.

Gestión de los negocios del Grupo de Empresas en su conjunto o de otro partícipe del Grupo de Empresas en particular, de manera que pueda implicar beneficio de ciertas categorías de acreedores.

Confusión de sus activos sociales o creación de una estructura social del Grupo de Empresas ficticia creando sociedades para eludir obligaciones legales o contractuales.

Descapitalización de la empresa de tal forma que no disponga del capital de trabajo requerido para la marcha de sus negocios, desde el momento de su constitución o a través del agotamiento de su capital por reembolsos indebidos a los accionistas o reparto anticipado de utilidades.

Manejos contables artificiosos o sin razonabilidad sobre valorizaciones, intangibles o diferidos.

Indebida variación de las condiciones de capitalización o capitalizaciones en especie.

Compensaciones, castigos de cartera, actos a título gratuito, capitalización de pasivos entre partícipes del Grupo de Empresas, transferencia de activos, pagos preferenciales, actos de competencia desleal así determinados por la autoridad competente, cesiones de créditos entre vinculados a favor de terceros, compra de créditos, manejo de precios, contratos excesivamente onerosos o actos de disposición entre los vinculados que no tengan justificación económica o jurídica. (...)". Resaltado en cursiva y subrayado por fuera de texto. 
(Numeral 1 $)^{41} \mathrm{y}$ sin que se logre explicar el significado existente de llegar a hacer "un gasto o en una demora injustificados".

Particularidad aquella que no es económica y jurídicamente aplicable, puesto que cualquier negocio jurídico acarreará un desembolso y un espacio, siendo factible que se presenten costos y tardanzas innecesarias y por tanto penetrables en el substrato material de la personalidad cuando se abuse de la misma para obtener un provecho para sí o para un tercero ${ }^{42}$.

Es por esto, por lo que en mi consideración no es suficiente levantar el velo de una persona moral por el simple hecho de no probar los gastos o demoras injustificado, en la medida que el fraud acarrea más que la conducta vana o sancionable administrativamente. Por tanto y como cierre de este artículo, mal puede concebirse el levantamiento del velo de un integrante del grupo, simplemente cuando no sea posible "deslindar la titularidad de los bienes sin incurrir en gastos o demoras injustificados".

\section{CONCLUSIONES}

El apremio del positivismo de los mercados ha llevado a exponer cierto grado de inconstitucionalidad por parte de los instrumentos que se han establecido para el desarrollo de las figuras económicas; eludiendo el trámite constitucional de elaboración o reforma de Leyes, pretendiendo dicha modificación a través de la expedición de Decretos Reglamentarios.

En la misma medida, valerse de instrumentos de distintos ordenamientos continentales e incluso de otros sistemas jurídicos es, de manera ineludible, una actividad merecedora de consideración, no obstante no puede procurarse su aplicabilidad sin antes entender en qué estado se han desarrollado las figuras que se pretenden traer a colación.

La técnica de disregard of the legal entity es una corriente que ha buscado romper el hermetismo del que están investidas las personas morales, por cuanto se está salvaguardando el patrimonio personal de los miembros que la integran, haciéndolos responsables exclusivamente hasta por el monto de lo aportado. Sin embargo, aquella técnica nació a la vida jurídica para el caso en que se hubiese logrado obtener un provecho para si o un tercero, abusando de aquella personalidad jurídica.

Existen los mecanismos y las acciones jurídicas idóneas para hallar la responsabilidad de los órganos de administración de las personas jurídicas; no

41 Ver Pie de Página No. 33.

42 En mi concepto y bajo el levantamiento del velo corporativo solo cabría abusar de la personalidad jurídica cuando de los asociados se trata, por cuanto si aplica dicho abuso a un administrador estaremos en presencia de alguna de las acciones de responsabilidad. 
es oportuno ni apropiado el cálculo de la responsabilidad del administrador a través de una técnica como la del allanamiento de la personalidad jurídica.

Es inadecuado alterar el orden jurídico mercantil, al valerse de una concepción primitiva en la medida que el fenómeno económico de los grupos, concebidos como agrupaciones de personas (morales y físicas) adheridas a un control alrededor de la misma dirección unitaria, no logran ser comprendidas de esta manera sino que por el contrario y como sucede en el Ordenamiento colombiano, el grupo es una simple situación de control.

\section{BIBLIOGRAFÍA}

BOLDÓ RODA, Carmen. Levantamiento del Velo y Persona Jurídica en el Derecho Privado Español. Edición 3. ${ }^{a}$ ed. Aranzadi. Navarra. 2000.

CERAMI Pietro, DI PORTO, Andrea y PETRUCCI, Aldo. Diritto Comerciales Romano. Profilio Storico. Edición 2. a ed. G. Giappichelli Editore. Torino. 2004.

CUBILLOS GARZÓN, Camilo Enrique. La Teoría del Levantamiento del Velo Corporativo en los Grupos Societarios. Universidad Externado de Colombia. Bogotá. 2016.

CUBILLOS GARZÓN, Camilo Enrique. ¿Profesionalización de un Encargo Societario? Universidad Externado de Colombia. Departamento de Derecho Comercial. Revist@ E-Mercatoria Vol. 9, n. ${ }^{\circ}$ 2. 2010.

CUBILLOS GARZÓN, Camilo Enrique. Comentarios en torno al Allanamiento de la Personalidad Jurídica en las Sociedades por Acciones Simplificadas. Universidad Externado de Colombia. Departamento de Derecho Comercial. Revist@ E-Mercatoria Vol. 8, n. ${ }^{\circ}$ 2. 2010.

DE ANGEL YAGÜEZ, Ricardo. La Doctrina del "Levantamiento del Velo" de la Persona Jurídica en la Jurisprudencia. 4. . ed., Civitas. Madrid. 1997.

EMBID IRUJO, José Miguel. Abuso de la Forma Social y Levantamiento del Velo del personalidad Jurídica: Algunas Reflexiones desde el Derecho Español. En Abuso de la Personalidad Societaria. Revista de Derecho Privado y Comunitario 20083. ${ }^{a}$ ed., Rubinzal-Culzoni Editores. Buenos Aires. 2009.

EMBID IRUJO, José Miguel. Introducción al Derecho de los Grupos de Sociedades. Comares. Granada, 2003.

GIRGADO PERANDONES, Pablo. La Empresa de Grupo y el Derecho de Sociedades. Comares. Granada. 2001.

GUZMÁN BRITO, Alejandro. Derecho Privado Romano. Vol. 2. Ed. Jurídica de Chile. Santiago de Chile. 1996. 
IGLESIAS, Juan. Derecho Romano. Instituciones de Derecho Privado. Sexta Edición. Ed. Ariel. Barcelona. 1972.

MANÓVIL, Rafael Mariano. Evolución del Derecho de los Grupos de Sociedades. Biblioteca Academia Nacional de Derecho y Ciencias Sociales de Buenos Aires. Serie IV. Instituto de Derecho Empresarial. Buenos Aires: La Ley, 2005. XIV, 130p.

MAZEAUD, Henri y León y TUNC, Andre. Tratado Teórico y Práctico de la Responsabilidad Civil Delictual y Contractual. Tomo I. Volumen II. Ediciones Jurídicas Europa - América. Buenos Aires. 1962.

NAMÉN VARGAS, William. Despersonificación y Responsabilidad Societaria. Congreso Internacional. La Despersonificación Societaria y el Régimen de la Responsabilidad. Pontificia Universidad Javeriana. Bogotá. 2004.

NARVÁEZ GARCÍA, José Ignacio. Teoría General de las Sociedades, 3ª ed., Bogotá Editorial Librería del Profesional. 1980

NEPPI, Vittorio. Causalidad Jurídica y Representación. Ediciones Jurídicas Europa - América. Buenos Aires. 1962.

PETIT, Eugene. Tratado Elemental de Derecho Romano. Novena edición. Editorial Cholos. Buenos Aires. 1924.

PINO SOLANO, María Mónica; HENAO BELTRÁN, Lina Fernanda; ARIAS BARRERA, Ligia Catherine y CUBILLOS GARZÓN, Camilo. Directrices del Régimen de Responsabilidad de los Administradores de Sociedades. Universidad Externado de Colombia. Departamento de Derecho Comercial. Revist@ E-Mercatoria Vol. 8, n. ${ }^{\circ}$ 1. Bogotá. 2009.

QUINCHE RAMÍREZ, Manuel Fernando. La elusión constitucional. Una política de evasión del control constitucional en Colombia. 2. ${ }^{a}$ ed. Ed. Universidad del Rosario. Bogotá. 2009.

RODRÍGUEZ MANCINI, Jorge. La Doctrina de la Penetración de la Personalidad Jurídica. Responsabilidad de los Administradores y de los Grupos Económicos en la Jurisprudencia de la Cámara Nacional de Apelaciones del Trabajo. En Abuso de la Personalidad Societaria. Revista de Derecho Privado y Comunitario 2008-3. Edición 1a . Ed. Rubinzal-Culzoni Editores. Buenos Aires. 2009.

Sentencia 801-000015 de 15 de marzo de 2013 de la Superintendencia de sociedades.

Sentencia 801-000023 de 24 de mayo de 2013 de la Superintendencia de sociedades.

Auto 801-017366 de 10 de diciembre de 2012 de la de la Superintendencia de sociedades. 
Sentencia 800-000055 de 16 de octubre de 2013 de la de la Superintendencia de sociedades.

Sentencia C-865 de 2004 de la Corte Constitucional.

Sentencia del 19 de agosto de 1999 del Consejo de Estado.

Sentencia del 13 de noviembre de 1997 del Consejo de Estado.

SOTOMENTE MUJICA, David y CUBILLOS GARZÓN, Camilo. Teoría del Levantamiento del Velo Corporativo (Tesis de Grado). Universidad Externado de Colombia. Bogotá. 1997. 